\title{
Leukocyte telomere length throughout the continuum of colorectal carcinogenesis
}

\author{
Cornelia Zöchmeister ${ }^{1, *}$, Stefanie Brezina ${ }^{1, *}$, Philipp Hofer $^{1}$, Andreas Baierl ${ }^{2}$, Michael \\ M. Bergmann ${ }^{3}$, Thomas Bachleitner-Hofmann ${ }^{3}$, Judith Karner-Hanusch ${ }^{3}$, Anton \\ Stift ${ }^{3}$, Armin Gerger ${ }^{4}$, Gernot Leeb ${ }^{5}$, Karl Mach ${ }^{5}$, Sivaramakrishna Rachakonda ${ }^{6}$, \\ Rajiv Kumar ${ }^{6}$ and Andrea Gsur ${ }^{1}$ \\ ${ }^{1}$ Medical University Vienna, Department of Medicine I, Institute of Cancer Research, Vienna, Austria \\ ${ }^{2}$ University of Vienna, Department of Statistics and Operations Research, Vienna, Austria \\ ${ }^{3}$ Medical University Vienna, Department of Surgery, Vienna, Austria \\ ${ }^{4}$ Medical University of Graz, Division of Oncology, Department of Internal Medicine, Graz, Austria \\ ${ }^{5}$ Hospital Oberpullendorf, Burgenland, Austria \\ ${ }^{6}$ German Cancer Research Center, Division of Molecular Genetic Epidemiology, Heidelberg, Germany \\ *These authors have contributed equally to this work \\ Correspondence to: Andrea Gsur, email: andrea.gsur@meduniwien.ac.at \\ Keywords: telomere length; colorectal cancer; adenoma; cancer epidemiology \\ Received: September 08, $2017 \quad$ Accepted: January 31, $2018 \quad$ Published: February 07, 2018 \\ Copyright: Zöchmeister et al. This is an open-access article distributed under the terms of the Creative Commons Attribution \\ License 3.0 (CC BY 3.0), which permits unrestricted use, distribution, and reproduction in any medium, provided the original author \\ and source are credited.
}

\section{ABSTRACT}

Considering the high prevalence of colorectal cancer (CRC) and relatively high mortality there is strong interest in identification of clinically relevant biomarkers. Telomere shortening is supposed to contribute to genomic instability and crucially involved in process of carcinogenesis. Peripheral blood leukocyte (PBL) telomere length was previously investigated in several studies as potential biomarker for CRC but with controversial results. This prompted us to investigate relative PBL telomere length in association with different histological findings throughout the continuum of colorectal carcinogenesis in order to reflect the whole spectrum of putative CRC development in a large study involving 2011 individuals. The study based on the Colorectal Cancer Study of Austria (CORSA), including 384 CRC cases as well as ageand gender-matched 544 high-risk adenomas, 537 low-risk adenoma patients and 546 colonoscopy-negative controls. Relative expression of telomeric repeats and the single copy reference gene, albumin ( $T / S$ ratio) was determined using monochrome multiplex quantitative PCR (MMQPCR). Telomeres were found to be significantly longer in CRC patients compared to control subjects $\left(P=3.61 \times 10^{-6}\right)$. Yet, no significant differences in telomere length could be detected for high-risk $(P=0.05956)$ and lowrisk colorectal adenoma patients $(P=0.05224)$. In addition, results presented in this manuscript highlight the impact of various epidemiological factors on PBL telomere length and its involvement in CRC. However, further large studies also including colorectal adenomas are necessary to confirm these results.

\section{INTRODUCTION}

Colorectal cancer (CRC) is the third most common cancer in men and the second most common cancer in women worldwide. In Austria, the incidence is in the top third within the European Union [1]. Despite improvements in early detection and treatments, CRC still remains a major cause of cancer-related death [2]. 
Development of CRC is a multi-step process involving several genetic and epigenetic events [3]. It is widely accepted that shortening of telomeres plays a role in the early steps of colorectal carcinogenesis by promoting chromosomal instability [4].

Telomeres are non-coding hexameric nucleotide repeats (TTAGGG) at the ends of all linear eukaryotic chromosomes $[5,6]$. Along with the protein complex shelterin they form protective and highly conserved nucleoprotein structures that facilitate genomic stability and integrity [7]. Telomeric repeats can vary in size from 0.15 to 50 kilobases, a single-strand overhang at the 3' end forms a specific T-loop structure which prevents degradation and end-to-end fusion [8]. The end replication problem of telomeres causes progressive shortening of telomere length accompanying cell division, usually triggering apoptosis, cellular senescence or immortalization in somatic cells $[9,10]$.

Peripheral blood leukocyte (PBL) telomere length is generally inversely correlated with age [10]. Due to various environmental influences $[11,12]$ and genetic differences $[13,14]$, telomere length in leukocytes varies remarkably between individuals among the same age. The onset as well as the susceptibility to age-related diseases including cancer is widely accepted to be affected by this inter-individual variation of PBL telomere length [15].

Several studies have examined telomere length in relation to risk of different cancer entities since first studies suggested an association of shorter telomeres with increased risk of malignancy [16]. Regarding CRC, a recently published meta-analysis of observational studies could not reveal a decisive association with PBL telomere length and cancer risk [17]. Considering the development of CRC via the putative adenoma-carcinoma sequence [18], shorter telomeres have been reported in individuals with advanced polyps suggesting that PBL telomere length could potentially be applied as a biomarker for high-risk polyps, being direct precursors of CRC [19]. Yet, the role of PBL telomere length in high-risk as well as low-risk colonic polyps is sparsely studied.

Our study based on the Colorectal Cancer Study of Austria (CORSA) biobank investigates PBL telomere length in 2011 individuals including 384 CRC, 544 high-risk polyps, 537 low-risk polyps and 546 colonoscopy-negative controls. We aimed to unveil a potential association of PBL telomere length with different histological findings throughout the continuum of colorectal carcinogenesis. The complex relationship between CRC and PBL telomere length as well as inconclusive findings in the literature prompted us to investigate the effect of various epidemiological factors on PBL telomere length and its involvement in CRC. Better understanding telomere length alterations and influencing epidemiological factors in $\mathrm{CRC}$ and its premalignant precursors could give valuable new insights into this complex disease.

\section{RESULTS}

\section{Study population}

In total, 2006 participants, consisting of 383 CRC patients, 542 high-risk adenoma patients, 535 low-risk adenoma patients and 546 colonoscopy-negative controls were eligible for statistical analysis. The majority of participants could be assigned to the age groups between 50 and 80 years. Characteristics of the study population are presented in Table 1, relative values refer to distribution within each group.

\section{Relative telomere length}

Relative telomere length was expressed as ratio between telomere signals $(\mathrm{T})$ and single copy gene signals (S), yielding a relative $\mathrm{T} / \mathrm{S}$ ratio. Efficiency for both amplicons ranged between 97-105\%. Intra-plate variation for telomere signals ( $\mathrm{T})$ was found to be $\leq 1.9 \%$ and $\leq$ $0.9 \%$ for single copy gene signals (S). Inter-plate variation ranged around $5 \%$ for telomeric repeats and around 2\% for albumin gene. Samples with an average T/S ratio greater than 2.5 were not included in the study population, therefore 5 out of 2011 (corresponding to $0.2 \%$ of the study population) were not considered for analysis.

To evaluate the effect of histological status and covariates (age, sex, and smoking status) on relative telomere length, several regression models were tested. For all regression analyses, the colonoscopy-negative control group, female sex and current smoking status were used as reference categories. In the best suitable multiple linear regression model, the effect of explanatory (independent) variables (histological finding, age, sex smoking status) on relative telomere length as dependent variable, and two-way interactions between age and sex and age and smoking, respectively, were considered. Further possible interactions with histological status were not significant and were therefore not included in the calculated model (Table 2). Due to missing smoking data, 163 patients were excluded from regression analysis.

\section{Telomere length and histological status}

Patients with CRC presented a significantly longer telomere length than colonoscopy-negative controls $(P$ value $=3.61 \times 10^{-6}$, Table 2$)$. Relative telomere length ratio in high-risk and low-risk adenoma subgroups did not significantly differ from the control group $(P$-value $=$ 0.05956 for high-risk adenoma and 0.05224 for low-risk adenoma subgroup, Table 2). In Figure 1, the status-wise distribution of average $\mathrm{T} / \mathrm{S}$ ratios of each status group is depicted as boxplots. The differences of average T/S ratio compared to the control group (including confidence interval) demonstrated the significant and clearly evident variation between average $\mathrm{T} / \mathrm{S}$ ratio of $\mathrm{CRC}$ and control 
Table 1: Study population: distribution of cases and controls according to sex, age and smoking status

\begin{tabular}{lcccccc}
\hline & Controls & CRC & $\begin{array}{c}\text { High-risk } \\
\text { adenoma }\end{array}$ & $\begin{array}{c}\text { Low-risk } \\
\text { adenoma }\end{array}$ & $\begin{array}{c}\text { p-value (differences } \\
\text { between status groups) }\end{array}$ \\
\cline { 2 - 7 } Sex & N & $\mathbf{5 4 6}$ & $\mathbf{3 8 3}$ & $\mathbf{5 4 2}$ & $\mathbf{5 3 5}$ & $\mathbf{0 , 9 9 8 1}$ \\
feme & $\leq 40$ & $11(2 \%)$ & $8(2 \%)$ & $10(2 \%)$ & $9(2 \%)$ & 0,9725 \\
& $\leq 50$ & $36(7 \%)$ & $29(8 \%)$ & $37(7 \%)$ & $38(7 \%)$ & \\
& $\leq 60$ & $134(25 \%)$ & $86(22 \%)$ & $132(24 \%)$ & $132(25 \%)$ & \\
& $\leq 70$ & $152(28 \%)$ & $111(29 \%)$ & $150(28 \%)$ & $159(30 \%)$ & \\
\multirow{3}{*}{ Smoking } & $\leq 151(39 \%)$ & $215(40 \%)$ & $214(40 \%)$ & \\
& $\leq 80$ & $180(33 \%)$ & $120(31 \%)$ & $186(34 \%)$ & $182(34 \%)$ & \\
& $\leq 90$ & $33(6 \%)$ & $29(8 \%)$ & $27(5 \%)$ & $15(3 \%)$ & \\
& forrent & $57(10 \%)$ & $54(14 \%)$ & $116(21 \%)$ & $93(17 \%)$ & \\
& former & $163(30 \%)$ & $91(24 \%)$ & $174(32 \%)$ & $159(30 \%)$ & \\
& never & $309(57 \%)$ & $129(34 \%)$ & $233(43 \%)$ & $265(50 \%)$ & \\
& missing & $17(3 \%)$ & $109(28 \%)$ & $19(4 \%)$ & $18(3 \%)$ & \\
\hline
\end{tabular}

Table 2: Best model for effect of independent variables (coefficients) and selected interactions on relative telomere length

\begin{tabular}{|c|c|c|c|c|}
\hline \multicolumn{5}{|c|}{ Best Model: histological status + age, sex, smoking + interactions sex, smoking with age } \\
\hline \multirow{2}{*}{ Coefficients: } & & & & \\
\hline & Estimate & Std. Error & t value & $P$-value \\
\hline (Intercept) & 0.980710 & 0.021214 & 46.229 & $<2 \times 10^{-16^{* * *}}$ \\
\hline $\mathrm{CRC}$ & 0.079773 & 0.017166 & 4.647 & $3.61 \times 10^{-6 * * *}$ \\
\hline High-risk adenoma & 0.026909 & 0.014274 & 1.885 & 0.05956 . \\
\hline Low-risk adenoma & 0.027596 & 0.014207 & 1.942 & 0.05224 \\
\hline Age & -0.012486 & 0.001487 & -8.398 & $<2 \times 10^{-16 * * *}$ \\
\hline Sex male & -0.051949 & 0.011790 & -4.406 & $1.11 \times 10^{-5 * * *}$ \\
\hline Former smoker & 0.015836 & 0.019358 & 0.818 & 0.41344 \\
\hline Never smoker & 0.048524 & 0.018723 & 2.592 & $0.00963^{* *}$ \\
\hline Age:Sex male & 0.001750 & 0.001095 & 1.597 & 0.11033 \\
\hline Age:former smoker & 0.003296 & 0.001603 & 2.055 & $0.03998^{*}$ \\
\hline Age:never smoker & 0.003370 & 0.001514 & 2.226 & $0.02613^{*}$ \\
\hline
\end{tabular}

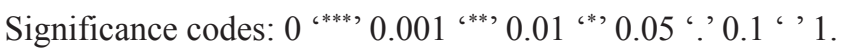

Residual standard error: 0.229 on 1832 degrees of freedom.

Multiple R-squared: 0.1564, Adjusted R-squared: 0.1518.

F-statistic: 33.97 on 10 and $1832 \mathrm{DF}$, p-value: $<2.2 \times 10^{-16}$.

The model includes main effects for histological status group, age, sex and smoking status plus two-way interactions between age and sex and age and smoking, respectively. Interactions with histological status were not significant and were therefore not included in the model. 
group. Fold changes (FCs), calculated based on the average $\mathrm{T} / \mathrm{S}$ ratio for control/CRC, control/high-risk adenoma and control/low-risk adenoma were 1.041, 1.022 and 1.024 , respectively.

A general distinction between the young $(\leq 64$ years) and old ( $>64$ years) age group did not contribute to any further significant differences in average $\mathrm{T} / \mathrm{S}$ ratio among patient subgroups.

\section{Inverse correlation between relative telomere length and age}

Average T/S ratios were inversely associated with age among all status groups, though no interaction between cases and controls could be observed (Figure 2).

Regarding sex, the accelerated telomere shortening with age was more pronounced in female than in male subjects (Figure 3). Although female patients showed higher $\mathrm{T} / \mathrm{S}$ ratios at younger age, telomere length seemed to converge to average male $\mathrm{T} / \mathrm{S}$ ratios over lifetime. However, this interaction between age and sex did not reach statistical significance in the regression model $(P$ value $=0.11033$, Table 2 ) .

In respect of smoking status, the inverse association between telomere length and age was most remarkable for subjects that were categorized as current smokers (Figure 4).

The most significant difference in telomere shortening could be shown between patients currently smoking and patients who had never smoked ( $P$-value $=0.02613$, Table 2). This effect increased with age. In addition, the telomere shortening in subjects with a former history of smoking was also found significantly different from those with no smoking history $(P$-value $=0.03998$, Table 2).

\section{DISCUSSION}

Considering the continuously high prevalence and relatively high mortality of CRC globally [20], there is a strong interest in the detection of potential clinical biomarkers. Especially the investigation of PBL telomere

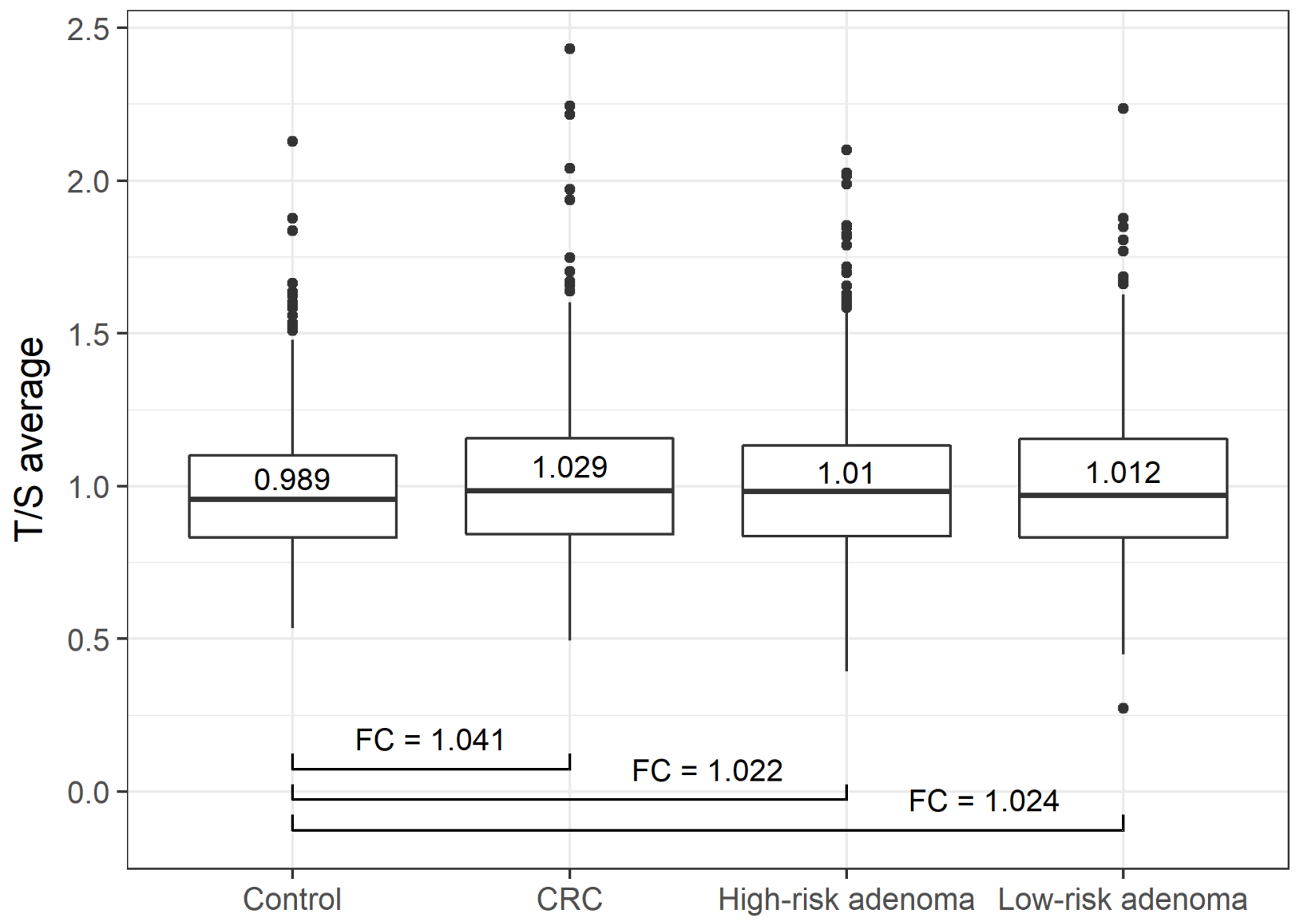

Figure 1: Status-wise distribution of average T/S ratios. Boxplots depict the distribution of average T/S ratios of each histological status group. $\mathrm{CRC}$ patients presented a significantly longer telomere length than controls $\left(P\right.$-value $\left.=3.61 \times 10^{-6}\right)$. Patients with high-risk and low-risk adenoma did not significantly differ from the control group $(P$-value $=0.05956$ and 0.05224 , respectively $)$. Fold changes $(F C s)$ are calculated based on the average $\mathrm{T} / \mathrm{S}$ ratio for control/CRC, control/high-risk adenoma and control/low-risk adenoma. 
length has been focused upon in order to identify high-risk groups for $\mathrm{CRC}$ and therefore spare the majority of the population colonoscopy. However, previous studies have found inconsistent associations between PBL telomere length and CRC so far.

Three prospective case-control studies could not reveal any association of telomere length with CRC [2123]. In the retrospective SEARCH Colorectal Study [21] as well as in a retrospective case-control study within the Chinese Han population [24] shorter mean PBL telomere length was associated with CRC risk. A comparably large study comprising $598 \mathrm{CRC}$ patients and 2,212 healthy controls found that younger individuals with longer PBL telomere or older individuals with shorter telomeres were associated with an increased risk for CRC [25]. Similarly, in the Shanghai Women's Study findings indicated an elevated risk for CRC in the presence of very short and very long telomere length, analyzing telomere length in peripheral blood of 441 women with CRC and 549 matched controls in a nested case-control approach [26].

Recently, a meta-analysis by Naing et al. examined the association between PBL telomere length and CRC risk, thereby including all of the above-mentioned studies. Neither in the prospective nor in the retrospective pooled analyses, an association between PBL telomere length and $\mathrm{CRC}$ risk could be ascertained. As only a limited number of studies was included in this meta-analysis, the authors emphasized that there is a continued need for large welldesigned studies on this topic [17].

Involving 2006 participants, our study is one of the largest investigating the association of PBL telomere length with $\mathrm{CRC}$ and its premalignant precursors. Here, we show that CRC patients present significantly longer PBL telomere length compared to colonoscopy-negative controls. As we have included cases as well as high- and low-risk polyps and a colonoscopy-negative control group, our study population reflects the adenoma-carcinoma

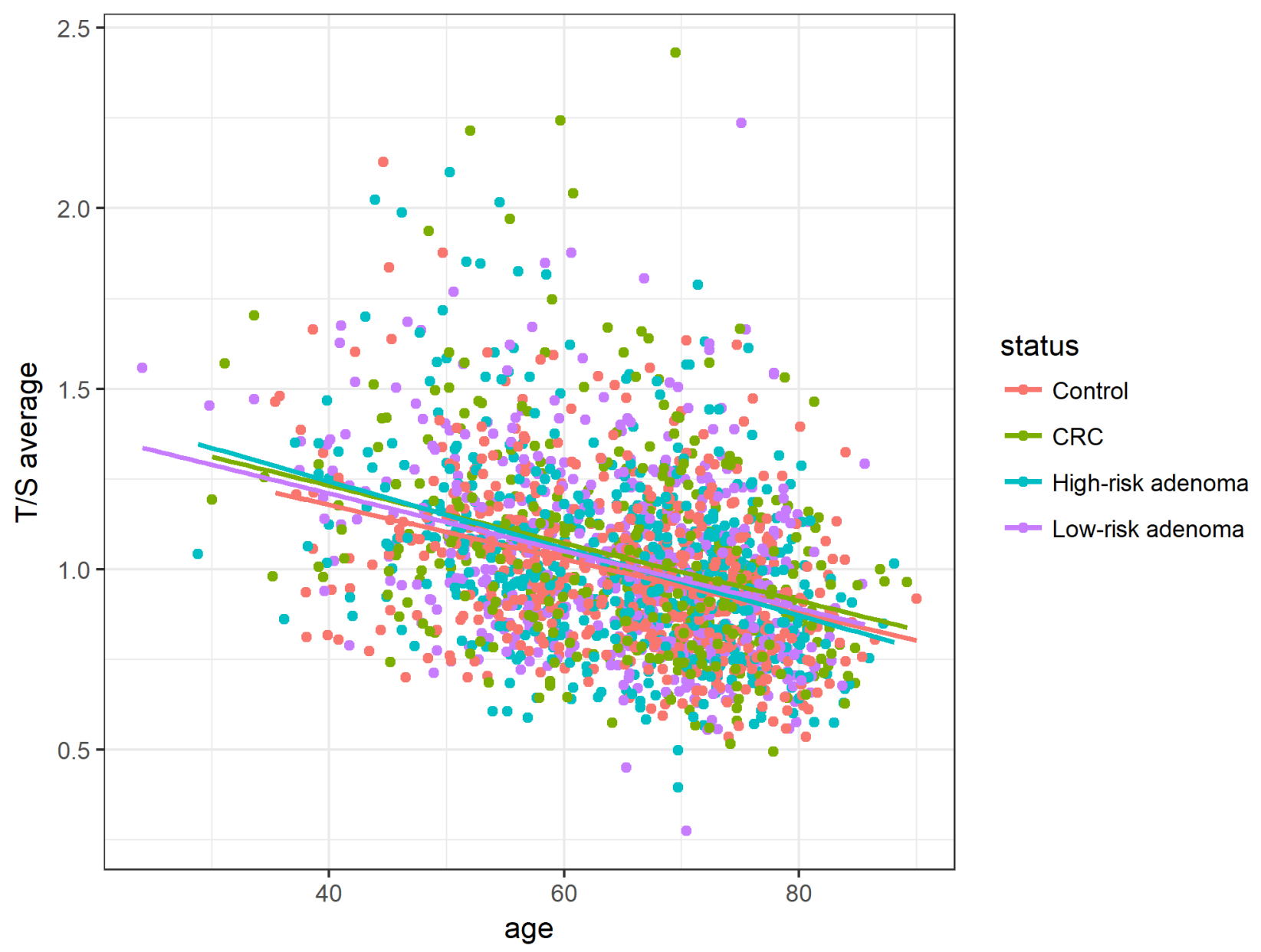

Figure 2: Association between age and relative telomere length for histological status groups (controls, CRC, high-risk adenoma and low-risk adenoma). Average $\mathrm{T} / \mathrm{S}$ ratios were inversely associated with age among all histological status groups. Linear equations and correlation values (CV): Controls: $1.75-0.011^{*} \mathrm{Age}(\mathrm{CV}:-0.36), \mathrm{CRC}: 1.88-0.013^{*} \mathrm{Age}(\mathrm{CV}$ : -0.32), High-risk adenoma: $1.87-0.013^{*}$ Age (CV: -0.39), Low-risk adenoma: $1.80-0.012^{*}$ Age (CV: -0.34). 
sequence to capture the whole spectrum of colorectal carcinogenesis. However, no statistically significant difference for the high-risk and low-risk polyps could be demonstrated in our study.

Telomere length data on PBL throughout the continuum of colorectal carcinogenesis has not been published in the literature so far. Only a small Spanish study investigated telomere length in the adenomacarcinoma sequence. However, telomere length of fresh tumor tissue instead of PBL was analysed from only 14 patients (6 tumor tissues, 8 polyps and normal mucosa) [27]. Regarding high-risk colorectal adenomas, one study found PBL telomere length to be shorter in patients manifesting advanced adenomas than in the colonoscopy-negative group. Nevertheless, sample sizes were considerably small, involving only 35 patients with advanced adenomas and 145 control patients. As no information on the time of blood sampling in relation to the development of advanced colorectal adenomas was provided, the validity of PBL telomere length for detection of advanced adenomas has to be considered [19].
Furthermore, in our study we also detected a significant correlation of PBL telomere length with age that is already known from vast evidence in literature $[10,11,25,26,28]$. Regarding sex, accelerated telomere shortening with age was generally more pronounced in women. Especially for younger female subjects a higher $\mathrm{T} / \mathrm{S}$ ratio was observed compared to their male counterparts, but converged with increasing age. Ageadjusted telomere length seemed to be influenced by gender, whereby the effect of the female hormone estrogen may be accountable for longer PBL telomere length in women $[29,30]$.

In terms of smoking habits, the inverse association between telomere length and age was most pronounced for subjects with a currently positive smoking status. Those individuals currently smoking presented significantly stronger telomere shortening with age compared to those subjects that had never smoked. A correlation between smoking and shortened PBL telomere length has already been demonstrated [31], with telomere attrition proportional to the number of cigarettes smoked

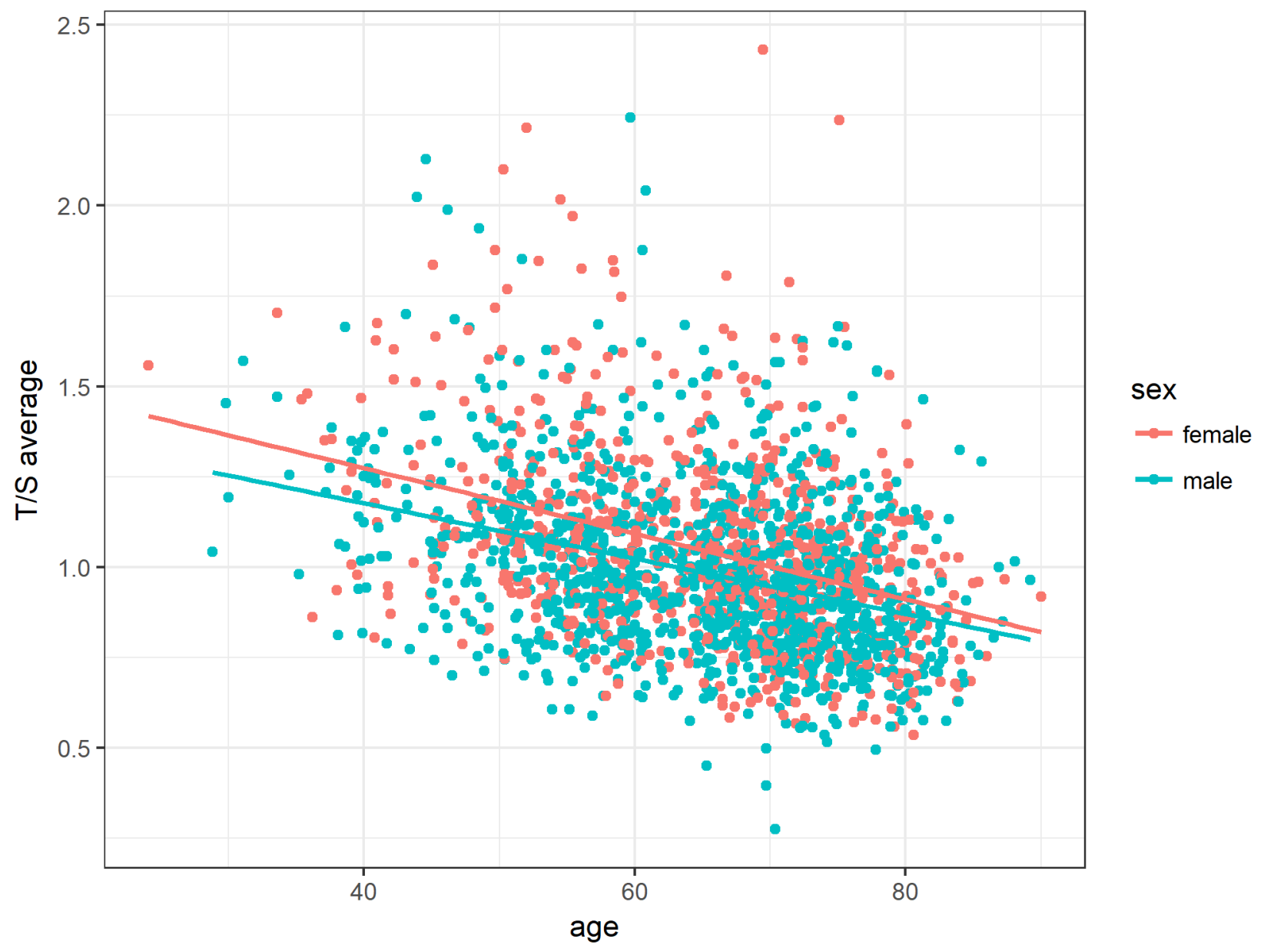

Figure 3: Association between age and relative telomere length for both sexes. The accelerated telomere shortening with age was more pronounced in women than in men. However, this interaction was tested as not statistically significant in the regression model. Linear equations and correlation values (CV): Female: 1.64 - $0.009^{*}$ Age (-0.37), Male: 1.64 - $0.009^{*}$ Age (-0.35). 
$[11,32]$. Cigarette smoke triggers oxidative stress and inflammation via the generation of free radicals, which could cause telomere erosion and consequently telomere shortening [33].

Besides the large sample size, our study benefits from our homogenous population-based control group selected from the B-PREDICT screening project and therefore known to be free of polyps and CRC. An equal sample collection and processing procedure guaranteed exclusion of methodological bias between subgroups. Furthermore, we used a stable and well-established method for telomere length measurement, a monochrome multiplex quantitative PCR (MMQPCR) based assay that compares telomere repeat copy number $(\mathrm{T})$ to single copy gene signals (S) (T/S ratio). Due to low intra- and interplate variation, high reproducibility and signal data consistency of our results was warranted. To exclude the fundamental confounding effect of telomere erosion following exposure to chemo- or radiotherapy $[34,35]$, our study only included previously untreated CRC patients to avoid modifications of PBL telomere length.

There are numerous reasons why epidemiological studies have shown controversial findings concerning a possible association between CRC risk and PBL telomere length so far. Differences are partly attributable to technical distinctions in DNA extraction methods [36], technical variations in PBL telomere length measurement methods [37], different study design e.g. retrospective versus prospective studies as well as limited study cohorts [38].

With respect to study design, a retrospective approach could have limited significance in terms of cause or consequence of telomere alterations and a possible reverse causation problem. It still remains unclear whether changes in telomere length in the blood result as a response during cancer progression or if the leukocyte telomeres itself contribute to the onset of CRC. In this regard, the time interval between sample collection and

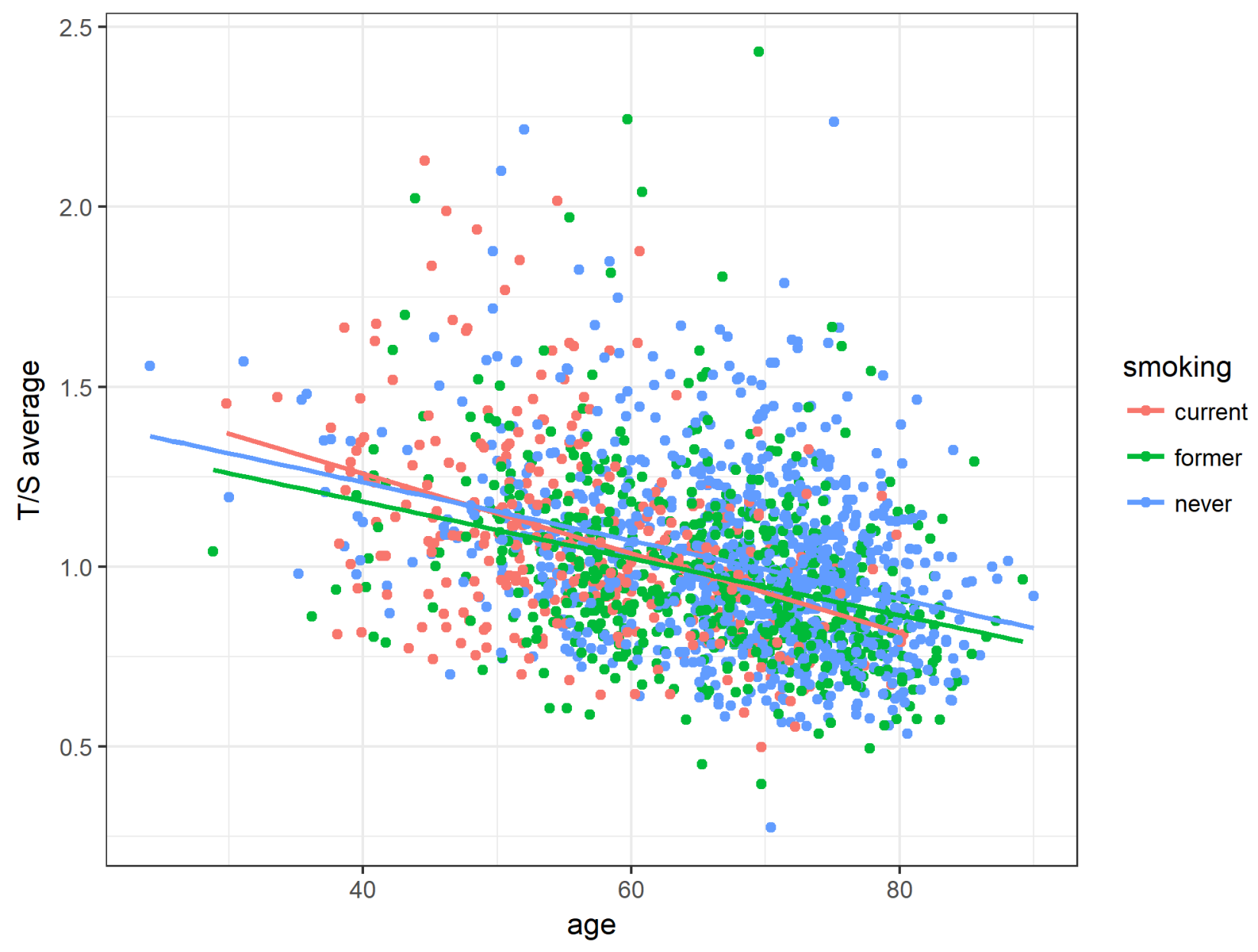

Figure 4: Association between age and relative telomere length according to smoking status. Average T/S ratios were inversely associated with age among all smoking groups. Linear equations and correlation values (CV): current smoker: 1.70 - $0.011{ }^{*}$ Age, former smoker: $1.50-0.008{ }^{*}$ Age, never smoker: $1.56-0.008{ }^{*}$ Age. 
cancer diagnosis may be also responsible for differences in published data [39].

Regarding its clinical implication, telomere length of leukocyte DNA may mirror telomere length in other healthy tissues and could therefore be a potential surrogate biomarker to assess the risk for CRC $[40,41]$.

Here, we could report an association between longer PBL telomere length and CRC, but not for its premalignant precursors. To enhance the understanding of CRC initiation and telomere length in the blood, epidemiological telomere research has to consider the multiple telomere dynamics. Several mentioned confounders might restrain the interpretation of the complex association between PBL telomere length and CRC development. Since the interindividual variation of telomere length is reasonably high among patients of the same age, this already indicates the difficulty of establishing a "normal range" of telomere length that could be applied as a clinical biomarker in CRC malignancy.

Yet, PBL telomere length remains a field of interest with the potential to contribute to early detection of CRC. In order to clarify the dynamics of PBL telomere length and its association with epidemiological factors in the initiation and progression of $\mathrm{CRC}$, large longitudinal studies could support its evaluation and suitability as prognostic indicator of CRC.

\section{MATERIALS AND METHODS}

\section{Study population}

In the ongoing Colorectal Cancer Study of Austria (CORSA) more than 14,000 participants, mainly Caucasians, have been recruited since 2003 [42]. In cooperation with the province-wide screening program "Burgenland Prevention Trial of Colorectal Disease with Immunological Testing” (B-PREDICT), all inhabitants of the Austrian province Burgenland aged between 40 and 80 years are invited to participate in faecal occult blood testing (FOBT) annually. FOBT-positive tested individuals are offered a complete colonoscopy and are asked to take part in CORSA at time of colonoscopy. Further CRC cases have been recruited at the Medical University of Vienna (Department of Surgery) and in three hospitals in Vienna and the Medical University of Graz (Department of Internal Medicine).

A blood sample and questionnaires assessing anthropometric and demographic factors were obtained. Clinical data are processed in a central database following standardized documentation guidelines. All subjects gave written informed consent and the study was approved by the institutional review boards.

Participants were grouped according to their most severe histological finding: colorectal cancer (CRC), highrisk adenoma, low-risk adenoma or colonoscopy-negative controls. The high-risk adenoma group included patients with adenomatous tubular-polyps $>1 \mathrm{~cm}$, adenomatous tubulo-villous polyps, adenomatous villous polyps, sessile serrated polyps (SSA) and traditional serrated polyps (TSA). Adenomatous tubular polyps $<1 \mathrm{~cm}$ were considered as low-risk polyps. Colonoscopy-negative controls had no polyps in their medical recording. Patients were stratified according to their age at time of blood sampling, coinciding with their most severe histological finding. Strata of five year intervals were formed ranging from the age of 40 to 90 years. Sample selection was performed on the basis of age- and gender-matched groups.

\section{DNA isolation}

Genomic DNA of CORSA participants was routinely purified from peripheral blood using the QIAamp DNA Blood Midi Kit (Qiagen, Valencia, CA, USA) and stored in our biobank at $-80^{\circ} \mathrm{C}$.

\section{Measurement of relative telomere length (RTL)}

Monochrome multiplex quantitative PCR (MMQPCR) experiments were performed to determine relative telomere length in peripheral blood leukocytes. Experiments were conducted in a high-throughput 384well plate format (ViiA 7 instrument, Applied Biosystems, Foster City, CA, USA). An adapted version of a previously described telomere length measurement qPCR protocol was applied [43]. Two sequential Real-Time PCR programs were used to generate telomere sequences $(\mathrm{T})$ as well as single copy reference gene, albumin, signals from the same well $(\mathrm{S})$, corresponding to the same amount of DNA.

A DNA pool of 30 CORSA control patients (involving all age groups) served as reference to generate standard curves for telomere and albumin runs. A serial dilution (1:2) was prepared to yield seven standards. Unknown telomere fragments (T) and albumin gene (S) of samples were measured in triplicates and quantified using the respective standard curves. Relative T/S ratios were calculated and indicated relative average telomere length.

Primers Telg ACACTAAGGTTTGGGTTTGGGT TTGGGTTTGGGTTAGTGT (200 nM) and Telc TGTT AGGTATCCCTATCCCTATCCCTATCCCTATCCCTAA CA (400 nm) were applied for telomere amplification; the primer pair Albuger2 CGGCGGCGGGCGGCGCGGGC TGGGCGGCCATGCTTTTCAGCTCTGCAAGTC (200 $\mathrm{nM}$ ) and Albdgcr2 GCCCGGCCCGCCGCGCCCGTCCC GCCGAGCATTAAGCT CTTTGGCAACGTAGGTTTC (400 nM) amplified the single copy gene albumin (SigmaAldrich, St. Louis, Missouri, USA). The fluorescent dye Syto 9 at a final concentration of $3 \mu \mathrm{M}$ (Life Technologies, Carlsbad, CA, USA) and the master mix 5X HOT FIREPol Probe qPCR Mix Plus with ROX (Solis BioDyne, Tartu, Estonia) were used. 
Real-time PCR conditions for telomere amplification were set as the following: $95^{\circ} \mathrm{C} / 15 \mathrm{~min}, 1$ cycle; $95^{\circ} \mathrm{C} / 20$ sec, $49^{\circ} \mathrm{C} / 1 \mathrm{~min}, 2$ cycles; $85^{\circ} \mathrm{C} / 20 \mathrm{sec}, 59^{\circ} \mathrm{C} / 30 \mathrm{sec}$ (signal acquisition), 25 cycles. For albumin gene amplification and melting curve analysis, the following thermal cycling profile was applied: $95^{\circ} \mathrm{C} / 15 \mathrm{sec}, 85^{\circ} \mathrm{C} / 30$ sec, $84^{\circ} \mathrm{C} / 30 \mathrm{sec}$ (signal acquisition), 35 cycles; $95^{\circ} \mathrm{C} / 15$ $\mathrm{sec}, 60^{\circ} \mathrm{C} / 1 \mathrm{~min}$ (continuous signal acquisition at $0.05^{\circ} \mathrm{C} /$ sec ramping); $95^{\circ} \mathrm{C} / 15 \mathrm{sec}$.

\section{qPCR quality control}

PCR efficiency for both amplicons was calculated based on the slope of the standard curves, according to the equation: $E=-1+\square 10 \Omega \wedge((-1 /$ slope $))$. Samples with a cycle threshold $(\mathrm{Ct})$ standard deviation above 0.5 were omitted from the analysis and repeated in an independent experiment. In each run, triplicates of standard samples were included twice. This allowed monitoring of intraplate as well as inter-plate variation.

\section{Statistical analysis}

A multiple linear regression model was estimated with histological status, gender and smoking status as categorical predictors and age as continuous covariate. The assumptions of linear regression were assessed by diagnostic plots. Descriptive statistics of confounding factors were derived per histological status. Apart from main effects, we tested for significant two-way interactions between predictors. All tests were two-sided and p-values less than 0.05 were considered statistically significant. All statistical analyses were performed with the statistical software R version 3.33 [44].

\section{Abbreviations}

Colorectal cancer (CRC), Peripheral blood leukocytes (PBL), Fold change (FC), Correlation value (CV), Colorectal Cancer Study of Austria (CORSA), Monochrome multiplex quantitative PCR (MMQPCR), Faecal occult blood testing (FOBT), High-risk polyps (HR), Low-risk polyps (LR), Sessile serrated polyps (SSA) and Traditional serrated polyps (TSA).

\section{CONFLICTS OF INTEREST}

The authors declare no conflicts of interest.

\section{FUNDING}

This study was funded by the "Herzfelder'sche Familienstiftung" (grant to A. Gsur).

\section{REFERENCES}

1. Ferlay J, Soerjomataram I, Dikshit R, Eser S, Mathers C, Rebelo M, Parkin DM, Forman D, Bray F. Cancer incidence and mortality worldwide: Sources, methods and major patterns in GLOBOCAN 2012. Int J Cancer. 2015; 136:E359-86.

2. Cunningham D, Atkin W, Lenz HJ, Lynch HT, Minsky B, Nordlinger B, Starling N. Colorectal cancer. Lancet. 2010; 375:1030-47.

3. Markowitz SD, Bertagnolli MM. Molecular origins of cancer: molecular basis of colorectal cancer. N Engl J Med. 2009; 361:2449-60.

4. Lengauer C, Kinzler KW, Vogelstein B. Genetic instability in colorectal cancers. Nature. 1997; 386:623-7.

5. Blackburn EH. The molecular structure of centromeres and telomeres. Annu Rev Biochem. 1984; 53:163-94.

6. Moyzis RK, Buckingham JM, Cram LS, Dani M, Deaven LL, Jones MD, Meyne J, Ratliff RL, Wu JR. A highly conserved repetitive DNA sequence, (TTAGGG)n, present at the telomeres of human chromosomes. Proc Natl Acad Sci USA. 1988; 85:6622-26.

7. Palm W, de Lange T. How shelterin protects mammalian telomeres. Annu Rev Genet. 2008; 42:301-34.

8. Griffith JD, Comeau L, Rosenfield S, Stansel RM, Bianchi A, Moss H, de Lange T. Mammalian telomeres end in a large duplex loop. Cell. 1999; 97:503-14.

9. Counter CM, Avilion AA, LeFeuvre CE, Stewart NG, Greider CW, Harley CB, Bacchetti S. Telomere shortening associated with chromosome instability is arrested in immortal cells which express telomerase activity. EMBO J. 1992; 11:1921-9.

10. Aubert G, Lansdorp PM. Telomeres and Aging. Physiol Rev. 2008; 88:557-79.

11. Valdes AM, Andrew T, Gardner JP, Kimura M, Oelsner E, Cherkas LF, Aviv A, Spector TD. Obesity, cigarette smoking, and telomere length in women. Lancet. 2005; 366:662-4.

12. Epel ES, Blackburn EH, Lin J, Dhabhar FS, Adler NE, Morrow JD, Cawthon RM. Accelerated telomere shortening in response to life stress. Proc Natl Acad Sci USA. 2004; 101:17312-5.

13. Vasa-Nicotera M, Brouilette S, Mangino M, Thompson JR, Braund P, Clemitson JR, Mason A, Bodycote CL, Raleigh SM, Louis E, Samani NJ. Mapping of a major locus that determines telomere length in humans. Am J Hum Genet. 2005; 76:147-51.

14. Slagboom PE, Droog S, Boomsma DI. Genetic determination of telomere size in humans: a twin study of three age groups. Am J Hum Genet. 1994; 55:876-82.

15. Lin J, Epel E, Blackburn E. Telomeres and lifestyle factors: roles in cellular aging. Mutat Res. 2012; 730:85-89. 
16. Wu X, Amos CI, Zhu Y, Zhao H, Grossman BH, Shay JW, Luo S, Hong WK, Spitz MR. Telomere Dysfunction: A Potential Cancer Predisposition Factor. J Natl Cancer Inst. 2003; 95:1211-8.

17. Naing C, Aung K, Lai PK, Mak JW. Association between telomere length and the risk of colorectal cancer: a metaanalysis of observational studies. BMC Cancer. 2017; 17:24.

18. Leslie A, Carey FA, Pratt NR, Steele RJ. The colorectal adenoma-carcinoma sequence. Br J Surg. 2002; 89:845-60.

19. Riegert-Johnson DL, Boardman LA, Crook JE, Thomas CS, Johnson RA, Roberts ME. Shorter peripheral blood telomeres are a potential biomarker for patients with advanced colorectal adenomas. Int J Biol Markers. 2012; 27:e375-80.

20. Bray F, Ren JS, Masuyer E, Ferlay J. Estimates of global cancer prevalence for 27 sites in the adult population in 2008. Int J Cancer 2013; 132:1133-45.

21. Pooley KA, Sandhu MS, Tyrer J, Shah M, Driver KE, Luben RN, Bingham SA, Ponder BA, Pharoah PD, Khaw KT, Easton DF, Dunning AM. Telomere length in prospective and retrospective cancer case-control studies. Cancer Res. 2010; 70:3170-6.

22. Lee IM, Lin J, Castonguay AJ, Barton NS, Buring JE, Zee RY. Mean leukocyte telomere length and risk of incident colorectal carcinoma in women: a prospective, nested casecontrol study. Clin Chem Lab Med. 2010; 48:259-62.

23. Zee RY, Castonguay AJ, Barton NS, Buring JE. Mean telomere length and risk of incident colorectal carcinoma: A prospective, nested case-control approach. Cancer Epidemiol Biomarkers Prev. 2009; 18:2280-2.

24. Qin Q, Sun J, Yin J, Liu L, Chen J, Zhang Y, Li T, Shi $\mathrm{Y}$, Wei S, Nie S. Telomere length in peripheral blood leukocytes is associated with risk of colorectal cancer in Chinese population. PLoS One. 2014; 9:e88135.

25. Boardman LA, Litzelman K, Seo S, Johnson RA, Vanderboom RJ, Kimmel GW, Cunningham JM, Gangnon RE, Engelman CD, Riegert-Johnson DL, Potter J, Haile R, Buchanan D, et al. The association of telomere length with colorectal cancer differs by the age of cancer onset. Clin Transl Gastroenterol. 2014; 5:e52-58.

26. Cui Y, Cai Q, Qu S, Chow WH, Wen W, Xiang YB, Wu J, Rothman N, Yang G, Shu XO, Gao YT, Zheng W. Association of leukocyte telomere length with colorectal cancer risk: nested case-control findings from the Shanghai Women's Health Study. Cancer Epidemiol Biomarkers Prev. 2012; 21:1807-13.

27. Valls Bautista C, Piñol Felis C, Reñé Espinet JM, Buenestado García J, Viñas Salas J. Telomerase activity and telomere length in the colorectal polyp-carcinoma sequence. Rev Esp Enferm Dig. 2009; 101:179-86.

28. Willeit P, Willeit J, Mayr A, Weger S, Oberhollenzer F, Brandstätter A, Kronenberg F, Kiechl S. Telomere length and risk of incident cancer and cancer mortality. JAMA. 2010; 304:69-75.

29. Mayer S, Brüderlein S, Perner S, Waibel I, Holdenried A, Ciloglu N, Hasel C, Mattfeldt T, Nielsen KV, Möller P. Sexspecific telomere length profiles and age-dependent erosion dynamics of individual chromosome arms in humans. Cytogenet Genome Res. 2006; 112:194-201.

30. Aviv A. Telomeres, sex, reactive oxygen species, and human cardiovascular aging. J Mol Med (Berl). 2002; 80:689-95. https://doi.org/10.1007/s00109-002-0377-8.

31. Huzen J, Wong LS, van Veldhuisen DJ, Samani NJ, Zwinderman AH, Codd V, Cawthon RM, Benus GF, van der Horst IC, Navis G, Bakker SJ, Gansevoort RT, de Jong PE, et al. Telomere length loss due to smoking and metabolic traits. J Intern Med. 2014; 275:155-63.

32. Astuti Y, Wardhana A, Watkins J, Wulaningsih W, and PILAR Research Network. Cigarette smoking and telomere length: A systematic review of 84 studies and meta-analysis. Environ Res. 2017; 158:480-89.

33. Asami S, Hirano T, Yamaguchi R, Tomioka $\mathrm{Y}$, Itoh $\mathrm{H}$, Kasai H. Increase of a type of oxidative DNA damage, 8-hydroxyguanine, and its repair activity in human leukocytes by cigarette smoking. Cancer Res. 1996; 56:2546-49.

34. Unryn BM, Hao D, Glück S, Riabowol KT. Acceleration of telomere loss by chemotherapy is greater in older patients with locally advanced head and neck cancer. Clin Cancer Res. 2006; 12:6345-50.

35. Schröder CP, Wisman GB, de Jong S, van der Graaf WT, Ruiters MH, Mulder NH, de Leij LF, van der Zee AG, de Vries EG. Telomere length in breast cancer patients before and after chemotherapy with or without stem cell transplantation. Br J Cancer. 2001; 84:1348-53.

36. Cunningham JM, Johnson RA, Litzelman K, Skinner HG, Seo S, Engelman CD, Vanderboom RJ, Kimmel GW, Gangnon RE, Riegert-Johnson DL, Baron JA, Potter JD, Haile R, et al. Telomere length varies by DNA extraction method: implications for epidemiologic research. Cancer Epidemiol Biomarkers Prev. 2013; 22:2047-54.

37. Hou L, Zhang X, Gawron AJ, Liu J. Surrogate tissue telomere length and cancer risk: Shorter or Longer? Cancer Lett. 2012; 319:130-35.

38. Prescott J, Wentzensen IM, Savage SA, De Vivo I. Epidemiologic evidence for a role of telomere dysfunction in cancer etiology. Mutat Res. 2012; 730:75-84.

39. Svenson U, Roos G. Telomere length as a biological marker in malignancy. Biochim Biophys Acta. 2009; 1792:317-23.

40. Butler MG, Tilburt J, DeVries A, Muralidhar B, Aue G, Hedges L, Atkinson J, Schwartz H. Comparison of chromosome telomere integrity in multiple tissues from subjects at different ages. Cancer Genet Cytogenet. 1998; 105:138-44. 
41. Friedrich U, Griese EU, Schwab M, Fritz P, Thon KP, Klotz U. Telomere length in different tissues of elderly patients. Mech Ageing Dev. 2000; 119:89-99.

42. Hofer P, Baierl A, Feik E, Führlinger G, Leeb G, Mach K, Holzmann K, Micksche M, Gsur A. MNS16A tandem repeats minisatellite of human telomerase gene: A risk factor for colorectal cancer. Carcinogenesis. 2011; 32:86671. https://doi.org/10.1093/carcin/bgr053.
43. Cawthon RM. Telomere length measurement by a novel monochrome multiplex quantitative PCR method. Nucleic Acids Res. 2009; 37:e21.

44. R Core Team. R: A language and environment for statistical computing. Vienna, Austria: R Foundation for Statistical Computing; 2017. 